\title{
Stroke Recurrence and its Prevention in Patients with Patent Foramen Ovale
}

\author{
J. U. Harrer, T. Wessels, A. Franke, S. Lucas, P. Berlit, C. Klötzsch
}

\begin{abstract}
Background: It is unclear whether medical or invasive (surgical or catheter interventional) treatment is preferable to prevent recurrence of cerebral ischemia in patients with patent foramen ovale (PFO) as the suspected cause of stroke and what the role of concomitant risk factors is in stroke recurrence. Methods: Over a period of ten years, 124 patients (mean age $51 \pm 15$ years) with cryptogenic cerebral ischemia and PFO were included into the study and prospectively followed over a mean of $52 \pm 32$ months. Of these, 83 were treated medically, 34 underwent transcatheter closure, and seven had surgical closure of the foramen. Of the medically treated patients, 11 stopped medication during follow-up. Recurrent ischemic events and risk factors for recurrence were analyzed. Results: Annual stroke recurrence rates were generally low and comparable in catheter and medically treated patients, and in patients who had stopped medication $(2.9 \% / 2.1 \% / 2.2 \% / y e a r)$. Patients suffering from recurrence after transcatheter closure $(\mathrm{n}=2)$ both had residual shunts. No stroke recurrence was observed in the few surgically treated patients. An atrial septal aneurysm was not a predictor of recurrent or multiple strokes $(\mathrm{p}>0.05, \mathrm{OR}=0.31$, and $\mathrm{OR}=0.74)$. Large shunts and a history of previous ischemic events were considerably more frequent in patients with recurrent strokes $(\mathrm{p}<0.05, \mathrm{OR}=5.0$, and $\mathrm{OR}=4.4)$. Pulmonary embolism and case fatality rates were significantly higher in patients with stroke recurrence $(p<0.001$, and $p<0.01)$. Conclusions: The absolute risk of recurrent cerebrovascular events in patients with PFO receiving medical or catheter interventional therapy is low. The small group of untreated patients had a comparably low rate of stroke recurrences. Previous ischemic events and shunt size were risk factors in this observational study. Given conflicting findings across multiple studies, enrollment into a randomized controlled trial would be the optimal choice.
\end{abstract}

RÉSUMÉ: La récidive de l'accident vasculaire cérébral et sa prévention chez les patients porteurs d'un foramen ovale perméable. Contexte: On ignore si le traitement médical ou le traitement effractif est préférable pour prévenir la récidive de l'ischémie cérébrale chez les patients porteurs d'un foramen ovale perméable (FOP) qu'on soupçonne être la cause d'un accident vasculaire cérébral (AVC) et quel rôle jouent les facteurs de risque concomitants dans la récidive de l'AVC. Méthodes: Cent vingt-quatre patients porteurs d'un FOP et ayant présenté une ischémie cérébrale cryptogénique ont été recrutés de façon prospective sur une période de 10 ans (âge moyen $51 \pm 15$ ans) et suivis pendant $52 \pm 32$ mois. Parmi ces patients, 83 ont été traités médicalement, 34 ont subi une fermeture du FOP par cathéter et 7 par chirurgie. Parmi les patients traités médicalement, 11 ont cessé de prendre la médication au cours du suivi. La récidive d'événements ischémiques et les facteurs de risque de récidive ont été analysés. Résultats: Le taux de récidive d'AVC était généralement faible et comparable chez les patients traités par cathéter et médicalement ainsi que chez ceux qui avaient cessé de prendre la médication $(2,9 \% ; 2,1 \% ; 2,2 \%$ par année respectivement). Les patients qui ont présenté une récidive après fermeture du FOP par cathéter $(n=2)$ avaient tous deux un shunt résiduel. Aucune récidive n'a été observée chez les patients traités chirurgicalement. Un anévrisme du septum auriculaire ne prédisait pas la récidive ou les AVC multiples ( $p>0,05$; rapport de cotes $=0,31$ et $=0,74$ ). Un shunt important et une histoire d'événements ischémiques antérieurs étaient beaucoup plus fréquents chez les patients qui présentaient des récidives d'AVC ( $\mathrm{p}<0,05$; rapport de cotes $=5,0$ et $=4,4)$. Les taux d'embolie pulmonaire et de décès étaient significativement plus élevés chez les patients qui présentaient une récidive d'AVC ( $\mathrm{p}<0,001$ et $\mathrm{p}<0,01)$. Conclusions: Le risque absolu de récidive d'AVC chez les patients porteurs d'un FOP traités médicalement ou par cathéter est faible. Le petit groupe de patients non traités avait également un taux de récidive bas, comparable à celui de ces deux autres groupes de patients. Les événements ischémiques antérieurs et l'importance du shunt étaient des facteurs de risque dans cette étude d'observation. Étant donné les observations discordantes provenant de nombreuses études, une étude randomisée serait la meilleure option.

Can. J. Neurol. Sci. 2006; 33: 39-47

Paradoxical embolism is an acknowledged cause of stroke in young patients with patent foramen ovale (PFO). ${ }^{1-4}$ Previous publications have addressed the suspected mechanisms of stroke, concomitant factors increasing the risk of embolic events and the available treatment options. ${ }^{5-13}$ In regard to stroke mechanism, most studies focus on paradoxical embolism and underlying deep venous thrombosis, which can be difficult to demonstrate. ${ }^{14-16}$ Nevertheless, other factors facilitating thrombus formation, such

\footnotetext{
From the Department of Neurology, Aachen University Hospital (JUH, SL, CK), Aachen, Germany; Department of Cardiology, Medical Clinic I, Aachen University Hospital (AF), Aachen, Germany; Department of Neurology, Justus-Liebig-University (TW), Giessen, Germany; Department of Neurology, Alfried Krupp Hospital (PB), Essen, Germany; Kliniken Schmieder Allensbach/Hegau Klinikum Singen (CK), Germany.

ReCEIVEd April 7, 2005. ACCEPTED In FinAl fORm August 27, 2005. Reprint requests to: Judith U. Harrer, Department of Neurology, RWTH Aachen University Hospital, Pauwelsstr. 30, 52074 Aachen, Germany.
} 
as dehydration, immobilization and hypercoagulable states are often documented. ${ }^{17}$ In older patients, anti-platelet therapy may be equally effective when compared with anticoagulation therapy. ${ }^{11}$ Many non-randomized studies of catheterinterventional closure suggest that this procedure has low periprocedural morbidity with possible prevention of stroke recurrence during mean follow-up periods of up to 2.6 years. $.^{9}, 18-$

${ }^{21}$ However, there are no long term results yet. Data on recurrent neurological events after surgical closure of a PFO demonstrate widely varying results: $0 \%-19.5 \%$. The procedure may account for a peri-operative morbidity of up to $18 \%$, including requirement for permanent pacemaker implantation. 5,6,8,22 Randomized trials comparing medical with catheter-based treatment are ongoing. We present data of PFO patients with ischemic stroke who were consecutively admitted over a period of ten years and followed for recurrent strokes with different treatment strategies.

\section{Materials and Methods}

\section{Patients}

Patients with cryptogenic stroke or transient ischemic attack (TIA) and a PFO were prospectively included in the study at two neurological departments (Aachen University Hospital and Alfried Krupp Hospital, Essen). The TIA patients with a history of migraneous headache or headache at the index event were excluded. The study conformed to the ethical guidelines of our institutions (in accordance with the 1964/2000 Declaration of Helsinki and the principles of Good Clinical Practice, 2002 version) and informed consent was obtained from all patients.

\section{Diagnostic work-up}

\section{General}

Diagnostic work-up comprised a cranial computerized tomography (CCT) and/or MRI on admission to detect cerebral ischemia and to exclude lacunar infarction. Follow-up imaging was carried out if clinical symptoms warranted. A history of previous cerebral ischemic events, thrombosis, pulmonary or systemic embolism, and cardiovascular risk factors was obtained. All patients had routine blood tests and those for coagulopathy.

PFO detection was performed with echocardiography or contrast transcranial Doppler sonography (TCD), depending on which diagnostic tool was available first. Evaluation of the shunt (degree, spontaneous or Valsalva-associated) was performed with contrast-TCD, whereas the exclusion of other cardioembolic sources (including atrial fibrillation, mitral or aortic valve disease, fibrin strands, left atrial or ventricular thrombus or tumor, akinetic segments of the left ventricle, and dilative cardiomyopathy) and atherosclerotic or nonatherosclerotic macroangiopathy was performed with echocardiography.

\section{Cardiac investigations}

Cardiac investigations included a 12-lead EKG, a 24-hourEKG, and echocardiography, either transesophageal (TEE, $\mathrm{n}=$ 101) or transthoracic (TTE, $n=23$ ). TTE was performed when patients refused TEE or had good transthoracic image quality.
TEE and TTE were performed with a Philips Sonos 4500 or 5500 duplex scanner and a $5-\mathrm{MHz}$ wide-band transducer. With the TTE, harmonic imaging was applied to improve detectability of right-to-left shunting. ${ }^{23}$ Imaging was performed in multiple planes $\left(0^{\circ} / 40^{\circ} / 110^{\circ}\right)$ during TEE and in an apical four-chamber view in TTE. To detect right-to-left shunting, repeated IV bolus injections of $10 \mathrm{ml}$ of agitated oxypolygelatine were administered into an antecubital vein. The procedure was carried out at rest and with Valsalva (five seconds duration); patients were trained prior to the procedure. Patient effort was verified if bulging of the atrial septum into the left atrium was observed. An atrial right-to-left shunt was diagnosed if at least five microbubbles (MB) appeared in the left atrium within three cardiac cycles after opacification of the right atrium either spontaneously or after the Valsalva maneuver. The TCD was used to determine the shunt size. An atrial septal aneurysm (ASA) was diagnosed if the atrial septum extended $>10 \mathrm{~mm}$ into the right or left atrium. ${ }^{24}$ All examinations were recorded on videotape.

\section{Vascular ultrasound investigations}

Patients underwent extracranial color-coded duplexsonography (ECCD; Philips Sonos 5500 duplex scanner with 5 $\mathrm{MHz}$ wide-band probe) as well as continuous wave Doppler sonography of the periorbital arteries and TCD to evaluate stenosis of brain supplying arteries (Multidop X4 with $2 \mathrm{MHz}$ and $4 \mathrm{MHz}$ probes, DWL).

To detect right-to-left shunting, patients were additionally evaluated with contrast-enhanced TCD "bubble test" (Echovist $300 ®$, Schering, Germany). The left middle cerebral artery was insonated at a depth of $50-55 \mathrm{~mm}$. In case of inadequate transtemporal insonation, the distal part of the left extracranial internal carotid artery was investigated. All patients were examined at rest and during a five second Valsalva strain; patients were trained prior to the actual procedure. Patient effort was verified by the decrease in intracranial blood flow as a result of increased intracranial pressure during the maneuver. The contrast agent was injected over five seconds just before the start of the Valsalva maneuver to achieve maximum contrast filling of the right atrium at the start of the maneuver. A MB was diagnosed when a typical visible and audible high intensity signal of short duration could be detected in the Doppler spectrum within six heart beats after injection of the contrast agent. With this technique, pulmonary shunts as a cause of rightto-left shunting can be largely excluded. ${ }^{25}$ The degree of shunting was categorized as small (1-10 MB), moderate ( $>10$ $\mathrm{MB}$ ), or large (a curtain of microbubbles within the Doppler spectrum $)^{25,26}$ (Figure 1). All examinations were recorded.

\section{Coagulation studies}

Coagulation studies included tests for activated protein $\mathrm{C}$ (APC)-resistance, deficiency of antithrombin III, protein $\mathrm{C}$ and/or protein $\mathrm{S}$, and tests for antiphospholipid antibodies. Routine blood tests contained activated partial thromboplastin time (aPTT), international normalized ratio (INR) and platelet count. 

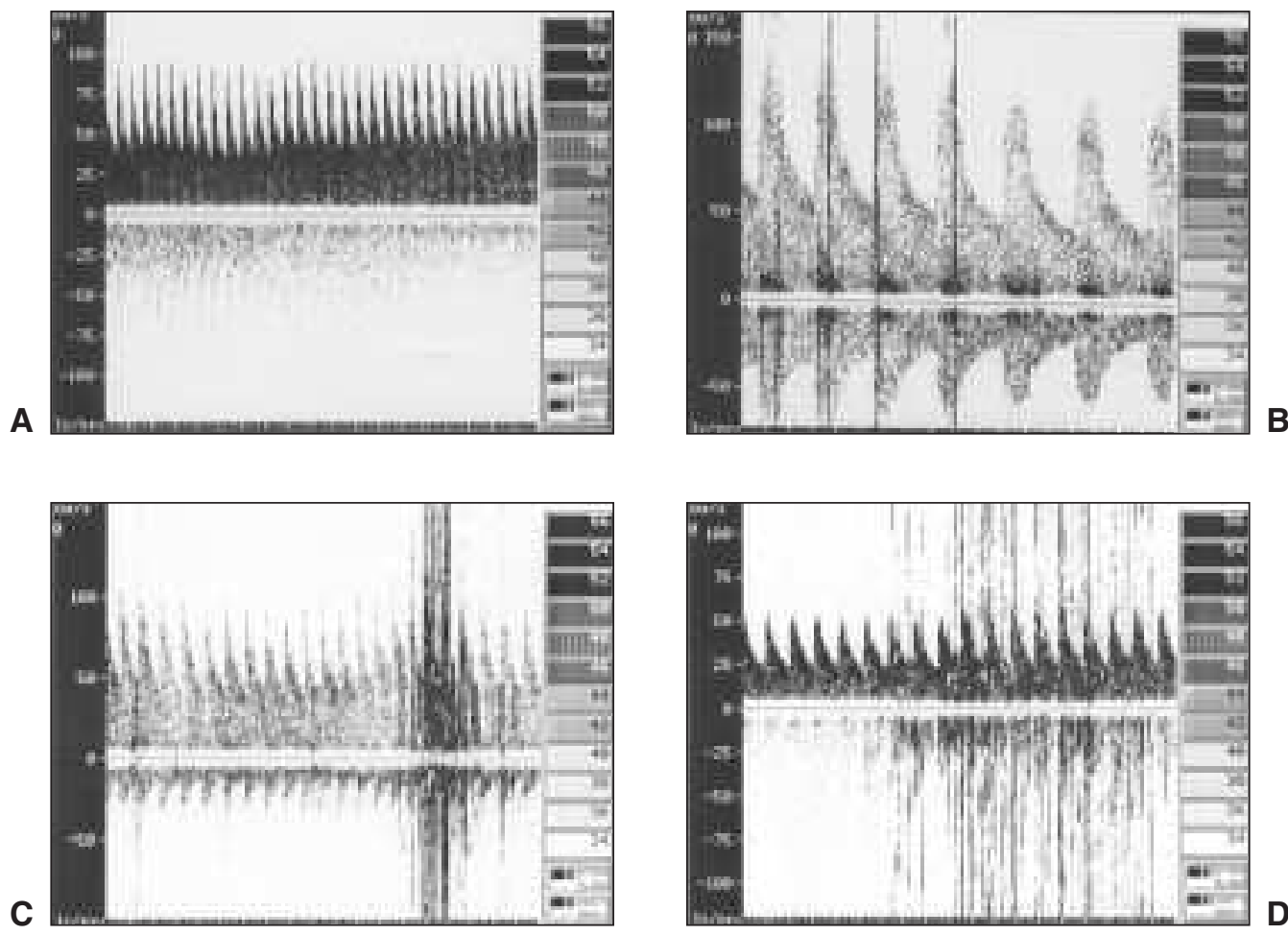

Figure: a) TCD bubble test: no shunt. b) TCD bubble test: small shunt. c) TCD bubble test: moderate shunt. d) TCD bubble test: large shunt.

\section{Investigations for deep venous thrombosis}

Risk factors contributing to thrombosis, such as dehydration (hematocrit $>50 \%$ ), immobilisation, recent surgery (within the previous six months), and malignancy were assessed. All patients were examined clinically for signs of deep venous thrombosis (DVT). Patients with clinical signs for DVT or risk factors for thrombosis, including abnormal coagulation studies, had phlebography and/or venous duplex sonography within one week of admission.

\section{Treatment and Follow-up}

Since randomized controlled trials are still ongoing, decision to either close the PFO or use medical therapy was made with patient consent. Devices used for catheter based closure were the Rashkind $\AA$, the ASDOS ${ }^{\circledR}$ and the Sideris ${ }^{\circledR}$ buttoned device in the early phase of the study and the Amplatzer ${ }^{\circledR}$, the CardioSEAL ${ }^{\circledR}$ and the PFOStar ${ }^{\circledR}$ systems in the later phase. Repeat control-TEE investigations were carried out after catheter based closure and after surgical closure. In medically treated patients, the decision to treat with either antiplatelet or anticoagulant therapy was made on the basis of the presence of DVT. If DVT was present, antiplatelet therapy was started after a six month course of anticoagulation therapy. In patients with thrombophilic disorders, lifetime systemic anticoagulation was chosen. - The first follow-up visit was scheduled to be at three to six months after inclusion into the study. Each patient underwent contrast-TCD at this time. Further follow-up was undertaken either by regular appointments in our outpatient departments or by telephone interviews with a standardized questionnaire at intervals between one month and two years. History and neurological symptoms of recurrent ischemia were obtained and follow-up imaging performed if recurrent ischemia was suspected. - In the event of recurrent cerebral ischemia, patients who were not hospitalized in our departments were seen in our neurological outpatient clinic as soon as possible and the patient's chart and cranial CT/MRI or the corresponding reports from the outside clinic were reviewed. Cranial CT or MRI was performed in all patients with recurrent events. The following outcome events were documented: recurrent cerebral ischemia (TIA and stroke), thrombosis, systemic or pulmonary embolism, and death. Compliance with medical therapy was also assessed. Follow-up period was defined as the time from inclusion into the study to the last patient contact (face-to-face or by telephone).

\section{Statistics}

One-way analysis of variance (ANOVA) was used to compare demographic variables between the three different treatment groups and to compare mean age between patients with a single and recurrent or multiple ischemic events (multiple ischemic events included patients with either recurrence during the study or previous events before inclusion into the study). Differences in the rates of recurrent ischemic events between the treatment groups, and differences in the distribution of categorical 
variables (predisposing factors) between patients with a single and patients with recurrent or with multiple ischemic events were analyzed with Fisher's exact test. A binary logistic regression model was used to examine the effect of the variables regarding recurrent and multiple ischemic events. All analyses were twotailed and a value of $\mathrm{p}<0.05$ was considered statistically significant. Significant differences were expressed as odds ratios (with 95\% confidence intervals). All computations were performed using SPSS 11.5® and StatXact 5®.

\section{RESULTS}

\section{Patients}

A total of 124 patients (71 men, 53 women) with cryptogenic ischemia and a PFO were included into the study and followedup over a mean of $50 \pm 32$ months. Of these patients, 84 had suffered from cerebral infarction and 40 from a transient ischemic attack. In 19 patients, previous ischemic events could be additionally inferred either from history, neurological examination, or cerebral imaging (hypodense lesions consistent with an embolic infarction pattern). On admission, all patients had CCT and 42 patients additional MRI. An EKG, echocardiography, and vascular ultrasound investigations were obtained in all patients, 24-hour-EKG in $90 \%$ of the patients. Forty-one patients $(33 \%)$ also had cerebral angiography to rule out cerebral vasculitis as cause of stroke. Mean age was $51 \pm 15$ years, 43 patients $(35 \%)$ were aged 45 years or younger. Both centers recruited a nearly equal number of patients. Demographic data were not significantly different in the different treatment arms though medical therapy patients tended to be older (Table 1).

\section{PFO characteristics}

A shunt at rest was observed in 77 patients (62\%), a shunt only under Valsalva strain could be documented in 47 patients (38\%). In seven patients, echocardiography was negative but TCD was clearly and repeatedly positive (in five patients only under Valsalva strain and in two patients spontaneously). Patients were therefore diagnosed as having a right-to-left shunt, which goes along with a previous study stating that TCD may be more sensitive than TEE. ${ }^{27}$ Twenty-four patients had a large degree of shunting, 56 patients had a moderate degree of shunting, and in 44 patients the degree of shunting was small. Thirty patients had an ASA; of these, 11 received closure of the PFO.

\section{Deep venous thrombosis}

One hundred and two patients $(77 \%)$ had a venous duplex sonography and/or phlebography. In 22 (22\%) of these patients,

Table 1: Demographic data of patients under different treatment options

\begin{tabular}{|c|c|c|c|c|c|}
\hline Variable & $\begin{array}{l}\text { entire group } \\
\text { of patients } \\
(\mathrm{n}=124)\end{array}$ & $\begin{array}{c}\text { medical } \\
\text { therapy* } \\
(\mathrm{n}=83)\end{array}$ & $\begin{array}{l}\text { transcatheter } \\
\text { closure } \\
(\mathrm{n}=34)\end{array}$ & $\begin{array}{l}\text { surgical } \\
\text { closure } \\
(\mathrm{n}=7)\end{array}$ & $\mathrm{p} \dagger$ \\
\hline Age (years) & $51.1 \pm 15.2$ & $52.5 \pm 15.4$ & $49.5 \pm 14.5$ & $42.0 \pm 12.4$ & NS \\
\hline Male & $57.3 \%$ & $63.9 \%$ & $44.1 \%$ & $42.9 \%$ & NS \\
\hline \multicolumn{6}{|l|}{$C V R F \ddagger$} \\
\hline Hypertension & $23.4 \%$ & $27.7 \%$ & $17.6 \%$ & $0 \%$ & NS \\
\hline Diabetes & $4.0 \%$ & $4.8 \%$ & $2.9 \%$ & $0 \%$ & NS \\
\hline Smoking & $21.0 \%$ & $18.1 \%$ & $29.4 \%$ & $14.3 \%$ & NS \\
\hline Dyslipidemia & $8.1 \%$ & $6.0 \%$ & $8.8 \%$ & $28.6 \%$ & NS \\
\hline Prior stroke & $12.9 \%$ & $15.7 \%$ & $5.9 \%$ & $14.3 \%$ & NS \\
\hline$D V T^{* *}$ & $17.7 \%$ & $16.9 \%$ & $17.6 \%$ & $28.6 \%$ & NS \\
\hline \multicolumn{6}{|c|}{ Characteristics of first incident } \\
\hline Stroke & $67.7 \%$ & $68.7 \%$ & $58.8 \%$ & $100 \%$ & NS \\
\hline TIA & $32.3 \%$ & $31.3 \%$ & $41.2 \%$ & $0 \%$ & NS \\
\hline anterior & $63.7 \%$ & $59.0 \%$ & $76.5 \%$ & $57.1 \%$ & NS \\
\hline posterior & $36.3 \%$ & $41.0 \%$ & $23.5 \%$ & $42.9 \%$ & NS \\
\hline \multicolumn{6}{|c|}{ Shunt characteristics } \\
\hline $\begin{array}{l}\text { Valsalva- } \\
\text { depending }\end{array}$ & $37.9 \%$ & $43.4 \%$ & $26.5 \%$ & $28.6 \%$ & NS \\
\hline Large size & $19.4 \%$ & $15.7 \%$ & $26.5 \%$ & $28.6 \%$ & NS \\
\hline ASA assoc. $\dagger \dagger$ & $24.2 \%$ & $22.9 \%$ & $32.4 \%$ & $0.0 \%$ & NS \\
\hline
\end{tabular}

$*$ including patients who stopped medical therapy during follow-up; $\dagger$ one-way ANOVA; $\$$ CVRF $=$ cardiovascular risk factors; $* *$ DVT $=$ deep venous thrombosis, according to clinical signs and duplex sonography/phlebography; $\dagger \dagger$ ASA $=$ atrial septal aneurysm associated; TIA $=$ transient ischemic attack. 
Table 2: Thrombophilic disorders in 68 patients diagnosed at the index neurological event

\begin{tabular}{llc}
\hline Identified disorder & $\mathbf{n}$ & \% \\
\hline IgG Anticardiolipin antibodies & 2 & 2.9 \\
IgM Anticardiolipin antibodies & 7 & 10.3 \\
Lupus anticoagulant & 0 & 0 \\
APC resistance* & 2 & 2.9 \\
Protein C deficiency & 1 & 1.5 \\
Protein S deficiency & 1 & 1.5 \\
AT III deficiency $\dagger$ & 2 & 2.9 \\
Total $\neq$ & 14 & 21 \\
\hline
\end{tabular}

$*$ activated protein $\mathrm{C}$ resistance; $\dagger$ antithrombin III deficiency;

$\ddagger$ one patient had two disorders

a DVT could be diagnosed; thus, a DVT was present in nearly $18 \%$ of all patients in temporal relation to the ischemic event. Three of these patients also had a pulmonary embolism. In two more patients with pulmonary embolism during the hospital stay no DVT could be detected and an additional three patients had a history of previous pulmonary embolism (independent from the ischemic event that led to inclusion into the study). During follow-up, two patients that also suffered from a malignancy, had a DVT and pulmonary embolism in addition to recurrent stroke and died. Six patients had a previous history of DVT. No clinical signs for systemic embolism were observed.
Concomitant risk factors for thrombosis and paradoxical embolism

Thrombophilia was found in the hematological surveys of 14/68 (21\%) investigated patients. Table 2 gives detailed information on the identified disorders. Malignant disease was documented in six patients. An increased hematocrit was observed in 32 patients $(26 \%)$ and immobilization prior to the index event could be documented in 29 patients $(23 \%)$.

\section{Treatment and recurrent ischemic events}

Overall, 41 patients had closure of the PFO, seven surgical and 34 catheter based. The remaining patients (83) were exclusively treated with aspirin, ticlopidine, coumarin or subcutaneous heparin. In the follow-up evaluation at three to six months after inclusion in the study, all medically treated patients continued to have a PFO, and evaluation of catheter-based or surgical closure revealed incomplete closure with some degree of residual shunt in 11/34 (32\%) catheter-treated patients at this time-point and still at 12 months after inclusion in the study (except in one patient, who only had one investigation at the end of the study). None of the surgically treated patients had a residual shunt. There were no intervention- or operation related complications apart from small femoral hematomas in three of the catheter-treated patients. Eleven recurrent ischemic events (nine strokes and 2 TIAs) were documented. Of these, eight (six strokes and two TIAs) occurred in medically treated patients (one patient had two recurrences) and two in patients who had received catheter-based closure (both strokes). This resulted in an annual recurrence rate of $2.1 \% / y e a r$ in medically treated patients and $2.9 \% / y e a r$ in catheter treated patients $(p>0.05)$. In medically treated patients, annual recurrence rate for antiplatelet therapy and anticoagulant therapy was nearly equal (1.85 and $1.82 \% /$ year). Of the patients who had stopped their medication

Table 3: Treatment, follow-up time and recurrent neurological events in 124 patients

\begin{tabular}{lcccccc}
\hline Therapy & $\begin{array}{c}\text { Patients } \\
\text { treated } \\
(\mathrm{n})^{*}\end{array}$ & $\begin{array}{c}\text { Mean duration } \\
\text { of treatment } \\
\text { (months) }\end{array}$ & $\begin{array}{c}\text { Total duration of } \\
\text { treatment } \\
\text { (months) }\end{array}$ & $\begin{array}{c}\text { Recurrent } \\
\text { neurological } \\
\text { events (n) }\end{array}$ & $\begin{array}{c}\text { Annual } \\
\text { recurrence rate } \\
(\% / y e a r)\end{array}$ & $\mathrm{p}^{\dagger}$ \\
\hline Antiaggregant & 59 & 55 & 3248 & 5 & 1.85 & NS \\
Coumarin & 51 & 27 & 1318 & $2 \ddagger$ & 1.82 & NS \\
Heparin s.c. $\S$ & 3 & 6 & 18 & 1 & 66.67 & NS \\
Medical Overall & 113 & 87 & 4584 & 8 & 2.09 & NS \\
No Medication & 11 & 49 & 536 & 1 & 2.24 & NS \\
Transcatheter Closure & 34 & 25 & 842 & 2 & 2.90 & NS \\
Surgical Closure & 7 & 36 & 255 & 0 & 0 & NS \\
Total & 124 & 50 & 6219 & 11 & 2.03 & NS \\
\hline
\end{tabular}

* due to changes in treatment during follow-up some patients appear in more than one group. $\dagger$ Fishers’ exact test. $\ddagger$ in one patient. $\S$ subcutaneously administered heparin 
during follow-up ( $\mathrm{n}=11$ ), one had a recurrent stroke, leading to a comparable rate of recurrent cerebral ischemic events (2.2\%/year, $\mathrm{p}>0.05)$. No recurrence was observed in the seven surgically treated patients $(\mathrm{p}>0.05)$. Regression analysis showed none of the treatment options to be a predictor of stroke recurrence. However, there was a trend to recurrent ischemic events in patients with residual shunting after transcatheter closure $(\mathrm{p}=0.098)$. Age was not significantly different between patients with single, recurrent or multiple events $(\mathrm{p}>0.05)$. Details on treatment, follow-up time and recurrence rates for all patients are found in Table 3 .

\section{Risk factors for recurrent ischemic events}

Patients with recurrent ischemic events $(n=10)$ were compared to the 114 patients with no recurrence during followup; and patients who had multiple ischemic events $(n=25)$ were compared to the 99 patients with only isolated ischemic events. Patients with a history of previous cerebral ischemic events at the time of inclusion into the study had significantly more recurrences during follow-up than those without previous ischemic events $(\mathrm{p}<0.05)$. However, in regression analysis, previous ischemia failed to reach significance as a predictor for stroke recurrence $(\mathrm{p}=0.063, \mathrm{OR}=4.4,95 \% \mathrm{CI}=0.80-20.85)$.

A large degree of shunting was also found significantly more frequently in patients with recurrent ischemia during follow-up and in patients with multiple ischemic events $(\mathrm{p}<0.05)$. A large degree of shunting was a strong predictor for recurrent ischemia and multiple ischemic events $(\mathrm{p}<0.05, \mathrm{OR}=5.0,95 \% \mathrm{CI}=1.02$ 23.69 and $\mathrm{OR}=3.2,95 \% \mathrm{CI}=1.02-9.27)$.

There was no significant difference between medically treated patients with ASA and without ASA when considering recurrent ischemia and multiple ischemic events. In regression analysis, ASA was not a predictor of recurrent or multiple ischemic events $(\mathrm{p}>0.05, \mathrm{OR}=0.31,95 \% \mathrm{CI}=0.007-2.43$ and $\mathrm{OR}=0.74,95 \% \mathrm{CI}=0.20-2.33)$. There was also no significant difference in recurrent or multiple ischemic events between patients with either spontaneous or Valsalva-depending shunt. However, significantly more patients with a spontaneous shunt also had a large shunt ( $\mathrm{p}=0.01)$.

Thrombophilia (any of the following: Protein $\mathrm{C}$ and/or $\mathrm{S}$ deficiency, APC-resistance, AT-III deficiency and antiphospholipid antibodies) was not associated with stroke recurrence or multiple ischemic events. Malignancy was more frequently found in patients with recurrent ischemic events, but this was not statistically significant $(\mathrm{p}=0.093)$. There was also no significant difference for these patients in comparison with patients who had multiple ischemic events and no malignancy.

There was a strong association between recurrent and multiple ischemic events and death during follow-up $(\mathrm{p}<0.01)$. Three patients died following the recurrent ischemic event. Pulmonary embolism (PE) was more frequent in the group with recurrent and multiple ischemic events $(\mathrm{p}<0.001$ and $\mathrm{p}=0.001)$ (Table 4).

Table 4: Characteristics of patients with single versus recurrent and multiple ischemic events

\begin{tabular}{|c|c|c|c|c|c|}
\hline & $\begin{array}{l}\text { Single event } \\
\qquad \mathrm{n}=99\end{array}$ & $\begin{array}{l}\text { Recurrent event } \\
\text { during follow-up } \\
\mathrm{n}=10\end{array}$ & $\begin{array}{l}\text { Multiple events } \\
\text { (previous and } \\
\text { recurrent) } n=25\end{array}$ & $\mathrm{p}^{* \dagger}$ & $\mathrm{p}^{*}+$ \\
\hline Men & $53.5 \%$ & $80.0 \%$ & $72.0 \%$ & NS & NS \\
\hline Mean age (years) & $50+15$ & $58+8$ & $56+14$ & NS & NS \\
\hline \multicolumn{6}{|l|}{ Characteristics of first incident } \\
\hline Stroke & $67.7 \%$ & $80.0 \%$ & $68.0 \%$ & NS & NS \\
\hline TIA & $32.3 \%$ & $20.0 \%$ & $32.0 \%$ & NS & NS \\
\hline Anterior & $65.7 \%$ & $60.0 \%$ & $56.0 \%$ & NS & NS \\
\hline Posterior & $37.3 \%$ & $40.0 \%$ & $44.0 \%$ & NS & NS \\
\hline \multicolumn{6}{|l|}{ Shunt Characteristics } \\
\hline Valsalva depending & $37.4 \%$ & $20.0 \%$ & $40.0 \%$ & NS & NS \\
\hline Large Size & $15.2 \%$ & $50.0 \%$ & $36.0 \%$ & $=.017$ & $=.025$ \\
\hline ASA $\S$ associated & $25.3 \%$ & $10.0 \%$ & $20.0 \%$ & NS & NS \\
\hline \multicolumn{6}{|l|}{ Concomitant Factors } \\
\hline DVT $\mid$ at first incident & $18.2 \%$ & $40.0 \%$ & $16.0 \%$ & NS & NS \\
\hline PE I[ at first incident & $1.0 \%$ & $20.0 \%$ & $12.0 \%$ & $=.022$ & $=.026$ \\
\hline PE at any time during follow-up & $1.0 \%$ & $40.0 \%$ & $20.0 \%$ & $=.0002$ & $=.001$ \\
\hline Thrombophilia & $(10 / 44) 18.5 \%$ & (3/6) $50.0 \%$ & $(4 / 13) 23.5 \%$ & NS & NS \\
\hline Cancer & $4.0 \%$ & $20.0 \%$ & $8.0 \%$ & NS & NS \\
\hline Death & $1.0 \%$ & $30.0 \%$ & $16 \%$ & $=.002$ & $=.006$ \\
\hline
\end{tabular}

* one-way ANOVA (mean age), Fisher's exact test (all except mean age); $\dagger$ single versus recurrent event; $\$$ single versus multiple events; $\S$ atrial septal aneurysm; | deep venous thrombosis; II pulmonary embolism 


\section{Discussion}

Multiple studies in recent years on patients with PFO and otherwise unexplained stroke underline the controversy that still exists regarding the adequate treatment of these patients and the risk factors that lead to stroke recurrence. . $^{1-8,-12,14-17,18-22,28-32}$ However, long-term follow-up studies are not yet available. Two prospective randomized trials are currently ongoing and compare catheter-based closure with medical therapy. We present data on 124 patients who were medically, catheter-based or surgically treated and followed up over a mean time of 50 months. According to our knowledge this is the longest prospective, nonrandomized follow-up study in patients with cryptogenic stroke. The follow-up time is of particular importance since patients with a PFO associated with stroke are usually young and otherwise healthy, implying a relatively long life expectancy, especially when the outcome of interest is relatively rare..$^{33}$

Similar to findings of Mas and co-workers, ${ }^{10}$ we found a considerably low annual recurrence rate in medically treated patients (2.1\%/year) which was slightly lower than the recurrence rate after catheter-based closure (2.9\%/year), even though patients of the medical group tended to be older. This result bears even more importance since only two of the 16 patients with a history of previous strokes, which according to our results is a strong predictor of stroke recurrence, received transcatheter closure of the foramen. The reason to decide for medical therapy in these patients was mainly due to the patients' preference for medical therapy, allowing for self-selection bias. Incidence of an ASA and/or a large shunt - two factors associated with an increased risk of (cryptogenic) stroke according to some studies ${ }^{34-38}$ - were more equally distributed between the two groups. We conclude that although the risk profile may have been even slightly higher in the medically treated group (as a result of the non-randomized trial design), this treatment option was as good as catheter-based closure to prevent stroke recurrence. However, recurrent ischemic events in catheter-treated patients were only observed in cases where a residual shunt was present (which was large in both patients) and the association of residual shunts with recurrent ischemia, as demonstrated by Wahl, ${ }^{39}$ just failed to reach statistical significance $(p=0.098)$. In contrast, patients who had received successful catheter-based closure of the foramen did not suffer from any recurrent neurological event, but numbers are too small to draw any conclusions.

The failure rate of closure and the rate of intervention-related morbidity of a procedure have to be considered when the decision for a treatment is made. In our study, the overall rate of some residual shunt after catheter-based closure was 32\%, which is at the higher end of numbers reported in the literature $(0-34 \%)$ that depend on device design and follow-up time..$^{9,19,30,40,41}$ However, follow-up time was only six months in one patient with residual shunt and, perhaps even more important, residual shunts were more frequently found in the early phase of the study, where patients received device systems which are nowadays obsolete, such as the Rashkind $\AA$, the Sideris $\AA$ buttoned and the ASDOS ${ }^{\circledR}$ device. Employing PFO-Star ${ }^{\circledR}$ and Amplatzer® systems, we now see successful closure in $97 \%$ of our patients after six months. Congruent with previous studies, intervention-related morbidity was low. ${ }^{18,19,30}$

After surgical closure of the PFO, there were no residual shunts and no recurrent neurological events documented in this group, nor were there any operation-related complications. However, we refrain from suggesting surgical closure as a treatment option since the procedure is highly invasive, possesses potential severe side-effects and also because the number of surgically treated patients in the literature is small, as in our study ${ }^{5,6,8}$ This is further supported by our results, showing that antiplatelet therapy is nearly as effective as surgical therapy, consistent with the Lausanne study. ${ }^{42}$ In addition, we found antiplatelet therapy to be as effective as anticoagulative therapy with coumarin, comparable to the PICSS trial results. ${ }^{11}$ Thus, the risk of hemorrhagic complications associated with anticoagulant therapy can be avoided, although it remains difficult to explain how antiplatelet therapy leads to stroke prevention in PFO patients, assuming venous thrombosis as underlying pathomechanism. ${ }^{43}$

Interestingly, the rate of recurrent neurological events was also very low in the group of patients who had stopped their medication (2.2\%/year). Since the number of patients in this group was small, no definite conclusions can be drawn from this result.

Regarding the risk factors that lead to stroke recurrence, we found that the most important predictors for stroke recurrence were the size of the shunt, i.e. a large shunt and the history of preceding stroke or TIA. Both results are supported by previous studies. ${ }^{37,38,44,45}$ In contrast, no increased risk of stroke recurrence was observed in medically treated patients with ASA in our study. Opposite results (an associated ASA but not a large degree of shunting as a risk factor for recurrence) were reported by Mas et al. ${ }^{10}$ in a large prospective study, although their data imply that until the four year follow-up time point some patients may have been censored not only due to recurrent events but also due to having been lost to follow-up. (The number of patients at risk dropped from 51 to 25 patients from year one to year four, though only eight patients were censored due to a recurrent event). Thus, one could assume a bias in the calculated risk of recurrences, supposing that stroke-free patients rather than patients with recurrences were lost to follow-up. In contrast, Homma ${ }^{11}$ found neither ASA nor shunt size to be associated with a higher risk of recurrence in patients with medical treatment, although they studied a different study population with respect to age and cardiovascular risk factors. Our results are supported by a study of Anzola and co-workers ${ }^{46}$ who found the TCDestimated amount of right-to-left shunting to be an important risk factor for stroke relapse. Yet, the role of an associated ASA and shunt size remains unclear as reported in a recent major review. ${ }^{33}$

The importance of the history of previous ischemia was reported by Nedeltchev et $\mathrm{al},{ }^{45}$ who found that patients with multiple ischemic strokes before the diagnosis of PFO had a doubled annual rate of recurrent neurological events when compared to patients with first ever stroke. Congruent with these results, in our study the history of previous ischemic events was the second strongest factor associated with stroke recurrence $(\mathrm{OR}=4.4,95 \% \mathrm{CI}=0.80-20.85, \mathrm{p}=0.063)$. Remarkably, we found a strong association between recurrent or multiple ischemic events and death during follow-up. In addition, PE - either at the time of the initial event or subsequently - was more frequent amongst this group of patients; emphasizing the decisive role of DVT in these patients. 
The role of underlying DVT was also stressed by the fact that DVT was found in $22 \%$ of the investigated patients $(77 \%)$. This rather high number of diagnosed DVT, in comparison to other studies, is probably due to the early conduction of the diagnostic procedure (within a week of admission). ${ }^{14,15,47}$

A weakness of our risk analysis is the relatively small number of patients who received coagulation studies (68/124, 55\%). Therefore, it is highly unlikely that our non-significant results regarding hyper-coagulable states in PFO patients are representative, especially since the prothrombin G20210A mutation, one of the strongest genetic risk factors for DVT, and plasma total homocysteine, predisposing to venous thrombosis when elevated, were not analyzed. ${ }^{48-50}$ Interestingly, patients with malignancy had no previous events, but a higher rate of recurrence than PFO-patients without this non-inherited risk factor for thrombophilia. Thus one could assume that an acquired risk factor for thrombosis together with a pre-existing PFO may interact even at a higher age.

To summarize, in this, according to our knowledge, longest non-randomized prospective follow-up study of patients with cryptogenic stroke and PFO, we found that two main factors, shunt size and history of previous neurological events were strongly associated with stroke recurrence. A further factor significantly associated with stroke recurrence and multiple ischemic events is a PE - either at the time of the initial event or subsequently. Randomized trials are needed for a more definitive assessment of the contribution of concomitant risk factors to stroke recurrence and for decision regarding appropriate treatment.

\section{ACKNOWLEDGEMENTS}

The authors thank Prof. Dr. Klaus Willmes for his help with statistical analysis and Caleb Roberts for his thoughtful review of the manuscript.

\section{REFERENCES}

1. Lechat P, Mas JL, Lascault G, et al. Prevalence of patent foramen ovale in patients with stroke. N Engl J Med. 1988; 318: 1148-52.

2. Webster MW, Smith HJ, Sharpe DN, et al. Patent foramen ovale in young stroke patients. Lancet. 1988; II: 11-2.

3. Jeanrenaud X, Bogousslavsky J, Payot M, Regli F, Kappenberger L. Patent foramen ovale and cerebral infarction in young patients. Schweiz Med Wochenschr. 1990; 120: 823-9.

4. Overell JR, Bone I, Lees KR. Interatrial septal anomalies and stroke: a meta-analysis of case-control studies. Neurology. 2000; 55: $1172-9$.

5. Devuyst G, Bogousslavsky J, Ruchat P, et al. Prognosis after stroke followed by surgical closure of patent foramen ovale: a prospective follow-up study with brain MRI and simultaneous transesophageal and transcranial Doppler ultrasound. Neurology. 1996; 47: 1162-6.

6. Homma S, Di Tullio MR, Sacco RL, Sciacca RR, Smith C, Mohr JP. Surgical closure of patent foramen ovale in cryptogenic stroke patients. Stroke. 1997; 28: 2376-81.

7. Bogousslavsky J, Devuyst G, Nendaz M, Yamamoto H, Sarasin F. Prevention of stroke recurrence with presumed paradoxical embolism. J Neurol. 1997; 244: 71-5.

8. Dearani JA, Ugurlu BS, Danielson GK, et al. Surgical patent foramen ovale closure for prevention of paradoxical embolismrelated cerebrovascular ischemic events. Circulation. 1999; 100: 171-5.
9. Windecker S, Wahl A, Chatterjee T, et al. Percutaneous closure of patent foramen ovale in patients with paradoxical embolism long-term risk of recurrent thromboembolic events. Circulation. 2000; 101: 893-989.

10. Mas JL, Arquizan C, Lamy C, et al. Recurrent cerebrovascular events associated with patent foramen ovale, atrial septal aneurysm, or both. N Engl J Med. 2001; 345: 1740-6.

11. Homma S, Sacco RL, Di Tullio MR, Sciacca RR, Mohr JP. Effect of medical treatment in stroke patients with patent foramen ovale. Circulation. 2002; 105: 2625-31.

12. Khairy P, O'Donnell CP, Landzberg M. Transcatheter closure versus medical therapy of patent foramen ovale and presumed paradoxical embolism. Ann Intern Med. 2003; 139: 753-60.

13. Horton S, Bunch TJ. Patent foramen ovale and stroke. Mayo Clin Proc. 2004; 79: 79-88.

14. Ranoux D, Cohen A, Cabanes L, Amarenco P, Bousser MG, Mas JL. Patent foramen ovale: Is stroke due to paradoxical embolism? Stroke. 1993; 24: 31-4.

15. Stollberger C, Slany J, Schuster I, Leitner H, Winkler WB, Karnik $\mathrm{R}$. The prevalence of deep venous thrombosis in patients with suspected paradoxical embolism. Ann Intern Med. 1993; 119: 461-5.

16. Cramer SC, Rordorf G, Maki JH, et al. Increased pelvic vein thrombi in cryptogenic stroke: results of the paradoxical emboli from large veins in ischemic stroke (PELVIS) study. Stroke. 2004; 35: 46-50.

17. Rodriguez CJ, Homma S. Hypercoagulable states in patients with patent foramen ovale. Curr Hematol Rep. 2003; 2: 435-41.

18. Beitzke A, Schuchlenz H, Gamillscheg A, Stein JI, Wendelin G. Catheter closure of the persistent foramen ovale: mid-term results in 162 patients. J Interv Cardiol. 2001; 14: 223-9.

19. Martin F, Sanchez PL, Doherty E, et al. Percutaneous transcatheter closure of patent foramen ovale in patients with paradoxical embolism. Circulation. 2002; 106: 1121-6.

20. Braun MU, Fassbender D, Schoen SP, et al. Transcatheter closure of patent foramen ovale in patients with cerebral ischemia. J Am Coll Cardiol. 2002; 39: 2019-25.

21. Hung J, Landzberg MJ, Jenkins KJ, et al. Closure of patent foramen ovale for paradoxical emboli: intermediate-term risk of recurrent neurological events following transcatheter device placement. J Am Coll Cardiol. 2000; 35: 1311-6.

22. Guffi M, Bogousslavsky J, Jeanrenaud X, Devuyst G, Sadeghi H. Surgical prophylaxis of recurrent stroke in patients with patent foramen ovale. J Thorac Cardiovasc Surg. 1996; 112: 260-3.

23. Kuhl HP, Hoffmann R, Merx MW, et al. Transthoracic echocardiography using second harmonic imaging: diagnostic alternative to transesophageal echocardiography for the detection of atrial right to left shunt in patients with cerebral embolic events. J Am Coll Cardiol. 1999; 34: 1823-30.

24. Hausmann D, Mugge A, Becht I, Daniel WG. Diagnosis of patent foramen ovale by transesophageal echocardiography and association with cerebral and peripheral embolic events. Am J Cardiol. 1992; 70: 668-72.

25. Klötzsch C, Janssen G, Berlit P. Transesophageal echocardiography and contrast-TCD in the detection of a patent foramen ovale: experiences with 111 patients. Neurology. 1994; 44: 1603-6.

26. Jauss M, Zanette E. Detection of right-left shunt with ultrasound contrast agent and transcranial Doppler sonography. Cerebrovasc Dis. 2000; 10: 490-6.

27. Devuyst G, Despland PA, Bogousslavsky J, Jeanrenaud X. Complementarity of contrast transcranial Doppler and contrast transesophageal echocardiography for the detection of patent foramen ovale in stroke patients. Eur Neurol. 1997; 38: 21-5.

28. Nendaz MR, Sarasin FP, Junod AF, Bogousslavsky J. Preventing stroke recurrence in patients with patent foramen ovale: antithrombotic therapy, foramen closure, or therapeutic abstention? A decision analytic perspective. Am Heart J. 1998; 135: 532-41.

29. Landzberg MJ, Khairy P. Indications for the closure of patent foramen ovale. Heart. 2004; 90: 219-24. 
30. Bruch L, Parsi A, Grad MO, et al. Transcatheter closure of interatrial communications for secondary prevention of paradoxical embolism. Circulation. 2002; 105: 2845-8.

31. Onorato E, Melzi G, Casilli F, et al. Patent foramen ovale with paradoxical embolism: mid-term results of transcatheter closure in 256 patients. J Interv Cardiol. 2003; 16: 43-50.

32. Cujec B, Mainra R, Johnson DH. Prevention of recurrent cerebral ischemic events in patients with patent foramen ovale and cryptogenic stroke or transient ischemic attacks. Can J Cardiol. 1999; 15: 57-64.

33. Messe SR, Silverman IE, Kizer JR, et al. Practice parameter: recurrent stroke with patent foramen ovale and atrial septal aneurysm. Neurology. 2004; 62: 1042-50.

34. Cabanes L, Mas JL, Cohen A. Atrial septal aneurysm and patent foramen ovale as risk factors for cryptogenic stroke in patients less than 55 years of age. Stroke. 1993; 24: 1865-73.

35. De Castro S, Cartoni D, Fiorello M, et al. Morphological and functional characteristics of patent foramen ovale and their embolic implications. Stroke. 2000; 31: 2407-13.

36. Mattioli AV, Bonetti L, Aquilina M, Oldani A, Longhini C, Mattioli G. Association between atrial septal aneurysm and patent foramen ovale in young patients with recent stroke and normal carotid arteries. Cerebrovasc Dis. 2003; 15: 4-10.

37. Steiner MM, Di Tullio MR, Rundek T, et al. Patent foramen ovale size and embolic brain imaging findings among patients with ischemic stroke. Stroke. 1998; 29: 944-8.

38. Schuchlenz HW, Weihs W, Horner S, Quehenberger F. The association between the diameter of the PFO and the risk of embolic cerebrovascular events. Am J Med. 2000; 109: 456-62.

39. Wahl A, Meier B, Haxel B, et al. Prognosis after percutaneous closure of patent foramen ovale for paradoxical embolism. Neurology. 2001; 57: 1330-2.

40. Schwerzmann M, Windecker S, Wahl A. Percutaneous closure of patent foramen ovale: impact of device design on safety and efficacy. Heart. 2004; 90: 186-90.
41. Braun M, Gliech V, Boscheri A, et al. Transcatheter closure of patent foramen ovale (PFO) in patients with paradoxical embolism. Periprocedural safety and mid-term follow-up results of three different device occluder systems. Eur Heart J. 2004; 25: 424-30.

42. Bogousslavsky J, Garazi S, Jeanrenaud X, Aebischer N, Van Melle G. Stroke recurrence in patients with patent foramen ovale: the Lausanne study. Neurology. 1996; 46: 1301-5.

43. Levine M, Hirsh J. Hemorrhagic complications of long-term anticoagulant therapy for ischemic cerebral vascular disease. Stroke. 1986; 17: 111-6.

44. Hausmann D, Mugge A, Daniel WG. Identification of patent foramen ovale permitting paradoxical embolism. J Am Coll Cardiol. 1995; 26: 1030-8.

45. Nedeltchev K, Arnold M, Wahl A, et al. Outcome of patients with cryptogenic stroke and patent foramen ovale. J Neurol Neurosurg Psychiatry. 2002; 72: 347-50.

46. Anzola GP, Zavarize P, Morandi E, Rozzini L, Parrinello G. Transcranial Doppler and risk of recurrence in patients with stroke and patent foramen ovale. Eur J Neurol. 2003; 10: 129-35.

47. Stollberger C, Finsterer J, Slany J. Why is venous thrombosis only rarely detected in patients with suspected paradoxical embolism? Thromb Res. 2002; 105: 267-73.

48. Seligsohn U, Lubetsky A. Genetic susceptibility to venous thrombosis. N Engl J Med. 2001; 344: 1222-31.

49. Pezzini A, Del Zotto E, Magoni M, et al. Inherited thrombophilic disorders in young adults with ischemic stroke and patent foramen ovale. Stroke. 2003; 34: 28-33.

50. Lichy C, Reuner KH, Buggle F, et al. Prothrombin G20210A mutation, but not Factor $\mathrm{V}$ Leiden, is a risk factor in patients with persistent foramen ovale and otherwise unexplained cerebral ischemia. Cerebrovasc Dis. 2003; 16: 83-7. 